\title{
A cidade e a memória na intervenção estudantil em Coimbra
}

The city and memory in student intervention at Coimbra

La cité et la mémoire dans l'intervention des étudiants à Coimbra

\section{Rui Bebiano}

\section{OpenEdition}

\section{Journals}

Edição electrónica

URL: http://journals.openedition.org/rccs/1152

DOI: $10.4000 /$ rccs. 1152

ISSN: 2182-7435

\section{Editora}

Centro de Estudos Sociais da Universidade de Coimbra

\section{Edição impressa}

Data de publição: 1 Outubro 2003

Paginação: 151-163

ISSN: 0254-1106

\section{Refêrencia eletrónica}

Rui Bebiano, "A cidade e a memória na intervenção estudantil em Coimbra », Revista Crítica de Ciências Sociais [Online], 66 | 2003, colocado online no dia 01 outubro 2012, criado a 20 abril 2019. URL : http://journals.openedition.org/rccs/1152; DOI : 10.4000/rccs. 1152

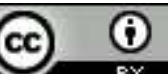




\section{RUI BEBIANO}

\section{A cidade e a memória na intervenção estudantil em Coimbra}

A partir da constatação de uma perda sistemática de memória colectiva ocorrida nas movimentações estudantis, procura-se mostrar como essa amnésia tem relativizado sempre a sua força. Ao concentrar-se a observação no caso de Coimbra, procede-se a um breve inventário histórico de alguns dos momentos decisivos da intervenção reivindicativa dos seus estudantes, em articulação com o lugar político e simbólico da própria cidade. Mencionando também a afirmação gradual de uma subcultura estudantil dotada de crescente autonomia e de alguma capacidade centrífuga em relação ao espaço universitário, apontam-se as tendências essenciais que aquela intervenção tem vindo a materializar.

1. Numa sociedade como a actual, que maltrata repetidamente a memória colectiva, o aluno universitário vive "concentrado em regra no seu tempo e sobre si mesmo, ignorante da história das universidades e do poder que os estudantes foram historicamente mantendo" (Boren, 2001: 20), limitando de alguma forma o alcance desse poder. De facto, no estudo das agitações estudantis deparamos sistematicamente com uma situação paradoxal. Se, por um lado, elas constituem um dos mais antigos movimentos sociais, sem dúvida fundamental na definição histórica dos equilíbrios verificados dentro dos diferentes espaços universitários e na evolução das estruturas políticas de numerosos países, por outro afirmam-se quase sempre de acordo com processos que tendem a desconsiderar o alcance das experiências antecedentes. Ao contrário do que tem acontecido com o movimento operário e sindical, sempre zeloso da lembrança dos seus heróis e dos seus difíceis combates, aqui a memória evapora-se, servindo quase exclusivamente, sob a forma de citações avulsas e algo inócuas, para legitimar a fortiori determinadas atitudes de circunstância.

A situação parece ainda mais bizarra por ocorrer junto de instituições vocacionadas para a salvaguarda e a transmissão do conhecimento, ocupadas justamente com a preservação da memória e a sua integração nos diversos mecanismos de compreensão. Sendo esta uma forma embaraçosa de lembrança, quase sempre evocadora da desordem, ela acaba por se ver aí muitas vezes omitida, ou então integrada em interpretações que lhe relativizam consideravelmente o alcance. Pode admitir-se, como hipótese, que 
este desconhecimento, quando transferido para o meio estudantil, se encontra na origem da recorrente capacidade que as suas iniciativas evidenciam - na presunção de que "a memória e o esquecimento são solidários, ambos necessários ao pleno emprego do tempo" (Augé, 2001: 105) - para reiterarem procedimentos com a candura e o voluntarismo próprios da primeira vez. Trata-se porém de uma situação que possui tanto de surpreendente quanto de constrangedor da eficácia e da própria inteligibilidade desses momentos. Perante uma história escrita e tornada pública pelos vencedores, como tal sempre manipulada por quem detém o poder, a intervenção da memória colectiva que é assumida por determinados grupos sociais pode sempre reintroduzir temas, hipóteses e capacidades entretanto entorpecidos, mas em condições de recobrarem uma parte do seu fulgor (Wieviorka, 1993). Ainda que tal aconteça, inevitavelmente, dentro de circunstâncias a todo o momento renovadas, solicitando do passado, principalmente, um papel de estímulo.

Semelhante amnésia detecta-se também no desenvolvimento das movimentações desta natureza que tiveram ou têm lugar em Portugal, e na grande dificuldade em integrá-las numa relação de contiguidade, apoiada na reminiscência que vão mantendo do papel desempenhado por aquelas que as precederam. Todavia, para além dessa inscrição dentro de uma tendência para a desmemória, que é de facto internacional, na relação com o ambiente social e político português o comportamento dos estudantes universitários tem vindo, ao longo dos anos, a desenvolver-se sob condições únicas, tornando ainda mais difícil a intelecção desse esquecimento.

Estas decorrem do facto de a instituição escolar coimbrã se ter mantido em lugar de exclusividade durante a maior parte da sua longa vida, com os privilégios, mas também com embaraços, próprios de quem cresce como filho único. Mesmo quando começou a deparar com concorrência, após o aparecimento das escolas superiores no decorrer do século XIX e depois com a iniciativa republicana da criação de estabelecimentos universitários congéneres, a "cidade dos estudantes", conservou, ainda assim, um lugar central na fixação das elites estudantis e na articulação funcional destas com o meio político e social envolvente. O percurso pessoal e político de Oliveira Salazar, tal como o de um grande número de figuras tutelares e orgânicas do Estado Novo, em particular aquelas que vieram das fileiras integralistas e da direita católica, a par do grande peso das práticas simbólicas mantidas até ao final do regime salazar-marcelista pela comunidade académica, não fizeram senão reforçar essa condição. Estes usos - comuns, como é sabido, à generalidade das sociedades académicas tradicionais (Bourdieu, 1984) - tornaram-se particularmente eficazes por se afirmarem 
dentro de uma sociedade fechada sobre si própria e acentuadamente hierarquizada como o era a coimbrã, regida por normas e valores de uma índole conservadora, prisioneira do hábito, e carente de alternativas fortes com as quais pudesse concorrer, capazes de relativizarem a influência dos factores de estagnação.

Tal conjuntura apenas começou a ser alterada de uma forma sensível a partir da década de 1950, devido em grande parte ao rápido aumento da população estudantil das universidades do Porto e principalmente de Lisboa, ao prestígio concorrente de algumas das suas escolas e mestres, e ainda a uma acentuada regionalização das matrículas nos estudos de Coimbra. De facto, durante o ano lectivo de 1963-64, já mais de metade destas provinha do distrito, chegando uma parte muito importante das restantes do remanescente espaço beirão (Nunes, 1968). Alguns anos depois, sob o regime democrático, acompanhando a explosão do ensino superior público e privado, este movimento virá ainda a acentuar-se, se bem que nas mitografias produzidas em áreas bastante expressivas dos imaginários universitário e citadino se tenham mantido, como emuladoras de uma controversa autoestima, as fábulas de um prestígio político e de um centripetismo cultural entretanto objectivamente alterados e, de uma certa maneira, bastante reduzidos.

O estudo de conjunto das movimentações estudantis portuguesas diferidas no tempo deve, pois, tomar em linha de conta uma dupla condição do espaço universitário conimbricense - assumido por vezes, em consequência desse esvaziamento da memória, de uma forma algo mitificada - ao longo da maior parte da sua existência. De um lado, a sua capacidade magnética, em condições de atrair durante um período dilatado um sector fundamental das elites, transformando a cidade na área nuclear da sua definição estrutural e simbólica. Do outro, a aptidão funcional que evidenciou, com capacidade para influenciar, directa ou indirectamente, os destinos nacionais. Ambas as linhas de força se foram manifestando através de uma sucessão de circunstâncias, dentro se torna possível anotar alguns momentos-chave.

2. Desde a época da fundação - quando os estudantes viviam já em bairro separado, do Arco de Almedina para cima, demarcando assim a fronteira social e reduzindo provisoriamente as hipóteses de conflito com os outros habitantes - até aos inícios do século XIX, não existe notícia de movimentações colectivas situadas fora da defesa dos privilégios e dos interesses pontuais da corporação estudantil. Mesmo as repetidas rixas, estúrdias e arruaças, que definiam um relacionamento por vezes muito violento com a população não académica - futrica como virá depois a ser designada - integravam este processo, resultando até, de algumas delas, o reforço das prer- 
rogativas académicas. $\mathrm{O}$ comportamento estudantil dispôs assim, durante séculos, de uma quase nula capacidade reivindicativa: no interior de uma sociedade rigidamente hierarquizada, o aluno universitário permanecia essencialmente submetido à ordem magistral, ocupado com uma preparação rudimentar para o lugar social de destaque que lhe estava segura e naturalmente reservado. A Universidade de Coimbra era pois, no que à sua função primordial dizia respeito, exclusivamente um alfobre de mandantes: "doutores" e "bacharéis" cujo simples título se afirmava, independentemente da efectiva qualificação, como indiscutível signo de autoridade e privilégio.

Esta condição começou a ser alterada apenas a partir da segunda metade de Oitocentos, de acordo com três tendências que uma iniciativa estudantil de natureza colectiva e índole conflitual irá assumir no decurso de um longo processo de afirmação pública aqui ocorrido.

A primeira delas tem a ver com a afirmação regular de formas de oposição, declarada e colectiva, às atitudes discricionárias ou a determinadas orientações das autoridades académicas. É neste contexto que se desenvolveram movimentações como aquela que levou à constituição da Sociedade do Raio (1861-1863) e, logo de seguida, aos acontecimentos da chamada Rolinada (1864). A Sociedade teve todas as condições para se definir até ao presente - não fora o mencionado escape de memória - como uma das referências centrais do movimento académico coimbrão: o secretismo que envolvia a sua organização, as iniciações nocturnas em lugares ermos, o grande apoio de que dispunha na academia, e, principalmente, a luta vitoriosa contra o detestado reitor Basílio Alberto, a valorização que atribuía à participação dos estudantes pugnando por "uma reforma que distinguisse ciência e costumes", o manifesto-proclamação "à opinião pública ilustrada do país", redigido por Antero e assinado por perto de metade dos 725 estudantes então matriculados (Nóvoa, 1991). Por sua vez, a Rolinada - relatada em Glória, a saborosa biografia do estudante arrivista J. C. Vieira de Castro (Valente, 2001), na qual intervieram ainda numerosos raístas - conduziu o movimento numa outra direcção, ultrapassando pela primeira vez os limites físicos da cidade. O êxodo de praticamente toda a academia para o Porto, onde se manteve, com escândalo do país, durante algumas semanas, esvaziando uma Coimbra dia e noite patrulhada por companhias armadas de infantaria, despojando-a da presença efectiva do seu símbolo maior e provocando tanto o pânico das autoridades nacionais e locais como a grave preocupação dos seus familiares mais zelosos, sublinhou, como jamais acontecera, a importância vital do estudante para a cidade, constituindo, porventura, o mais extremo acto de protesto estudantil alguma vez nela produzido. 
Em 1907, uma greve geral académica culminará a contestação das estratégias conservadoras desse "espírito universitário" que, com raras excepções, jamais fora capaz de se adaptar verdadeiramente às práticas e às exigências do liberalismo político e filosófico. Desencadeada pela reprovação de José Eugénio Dias Ferreira nas suas provas públicas de doutoramento - por ser filho de um importante opositor a João Franco, chefe do governo e ditador, e praticar um inconformismo que o levara a dedicar o trabalho apresentado a Teófilo Braga, proscrito de Coimbra - abrangeu rapidamente a generalidade da academia, principalmente após a expulsão dos alunos "intransigentes", que haviam tido um papel mais activo na organização dos protestos. Apesar de semi-derrotada, esta luta estudantil, repleta de mais uns tantos episódios rocambolescos, decorreu em função de um conjunto de factos e circunstâncias que lhe conferiram uma dimensão nacional, alargando-se a outras escolas superiores e aos liceus, sempre acompanhada de um amplo e inflamado debate a respeito da política educativa e da própria sociedade académica, com larga projecção na imprensa periódica da época (Xavier, 1962).

A segunda tendência preenchida pela iniciativa estudantil definiu-se através da sua intervenção empenhada na tentativa de suscitar mais directamente a alteração das políticas governamentais para a educação pública, em particular para a universitária. Possui igualmente momentos de grande dinamismo, em regra centrados, pela força das circunstâncias que implicavam uma maior vulnerabilidade do Estado, nos períodos de intensa instabilidade política. Primeiramente, aqueles que se seguiram à proclamação da República; depois durante os anos de uma "primavera marcelista" coincidente com a fase crítica e de declínio do Estado Novo; em seguida nos tempos imediatamente posteriores ao 25 de Abril; e, finalmente, em 1993, dentro de um contexto bastante diverso, quando o ministro "cavaquista" Couto dos Santos lançou a ideia da revogação do anterior regime de propinas, abrindo um conflito que permanece em aberto.

Logo em Outubro de 1910, Coimbra foi palco de movimentações destinadas a pôr em causa a ordem universitária vigente durante a monarquia. Os estudantes invadiram em fúria a Sala dos Capelos, fazendo os cadeirais em pedaços e rasgando as vestes dos lentes. No dia 23 desse mês, ao mesmo tempo que era suprimida a Faculdade de Teologia, abolia-se o foro académico e declarava-se facultativo o uso da capa e batina, terminando-se também com os cerimoniais académicos. Manuel de Arriaga, o recém-empossado reitor republicano, que em breve seria o primeiro presidente da República constitucionalmente eleito, e António José de Almeida, ministro do Interior, anunciarão, sem quaisquer insígnias universitárias, perante uma assembleia 
de lentes e estudantes reunidos sem distinção de nível na Sala dos Capelos, a confirmação destas e de outras medidas, num vislumbre simbólico, adaptado ao meio universitário, das profundas mudanças sociais e na organização do ensino que, antes ainda de iniciado o recuo de um republicanismo mais radical e jacobino, pareciam anunciar então um programa político em condições de ser levado a cabo.

Muitos anos mais tarde, em plena "crise académica" de 62, mas principalmente durante a fase conturbada vivida no ano lectivo de 1968-69, seriam de novo os estudantes de Coimbra a marcar a divergência perante o autoritarismo do regime, no que se refere à sua política educativa para o ensino superior. A forma razoavelmente ordeira que tomou a célebre manifestação do 17 de Abril de 1969 no edifício das Matemáticas, na presença da "veneranda figura do Chefe de Estado" e do seu ministro da Educação José Hermano Saraiva - apenas "irreverente" e "inadmissível" para um regime que se mantinha intransigentemente autoritário e esforçadamente autista -, bem como as palavras de ordem estudantis na altura avançadas, anunciavam esse projecto de, pela iniciativa do movimento estudantil, promover a mudança na política educativa do governo (Cruzeiro, 1989). Quando se requeriam fundamentalmente medidas no sentido de uma renovação da universidade e da "democratização", a par do respeito para com os dirigentes associativos eleitos e da proposta de reintegração de professores e alunos expulsos por motivos políticos, colocava-se a voz estudantil num espaço que até então a ignorava (Namorado, 1989), e a própria cidade no centro da contestação de uma política educativa e cultural com a qual as autoridades académicas, salvo raríssimas excepções, compactuavam sem grandes problemas.

Apenas a situação criada com a revolução de Abril viria, de facto, a propiciar a possibilidade de uma intervenção activa nesta área, se bem que, nessa altura, a voz reformadora dos estudantes - e particularmente a dos estudantes universitários - tivesse sido de alguma forma abafada por premências revolucionárias mais dificilmente adiáveis. De qualquer maneira, existe toda uma história da actuação estudantil no período imediatamente pós-revolucionário - desde o dia da abolição do regime salazar-marcelista até à promulgação do Decreto-lei n. ${ }^{\circ}$ 781-A/76, vulgarmente designado como "lei Cardia” - que se encontra inteiramente por fazer, mas sem a qual não será possível entender de forma cabal o desenvolvimento da vida universitária ao longo dos últimos trinta anos. Foi a confluência da tradição corporativa universitária com a intervenção de alguns dos objectivos do calendário revolucionário que criou as condições para a produção dos instrumentos da "gestão democrática das escolas" que, anos depois, associados em Coimbra 
a uns também conciliatórios e parcialmente ambíguos Estatutos da Universidade, consignados em 1989 por despacho normativo, produziram uma situação de bloqueio institucional em relação à intervenção dinâmica da iniciativa estudantil e à própria capacidade dos organismos gestionários, que ainda permanece activa.

Após a época que correspondeu sensivelmente à década de 1980, na qual prevaleceu um movimento dirigido por militantes dos destacamentos partidários juvenis (as "jotas"), quase exclusivamente centrado numa actividade meramente associativa, irá dar-se início à procura de um novo modelo de actuação. A luta estudantil contra o pagamento de propinas emergirá assim dentro de um contexto de indefinição programática, mas de nítida e crescente recusa da interferência dos partidos políticos. Uma orientação menos formal, então adoptada por alguns sectores politicamente desenquadrados da frente "anti-propinas" - a qual lhes valeu o qualificativo de actores de uma determinada "geração rasca" - resultou em larga medida desse processo de busca, que nos anos mais recentes tem vindo a possibilitar o crescimento de um movimento menos dependente de programas reivindicativos excessivamente localizados. No caso de Coimbra, a relativização do lugar outrora central da sua Alma Mater correspondeu também à moderação do papel, importante mas já não decisivo, do segmento nativo de uma iniciativa estudantil agora dotada de dimensão claramente nacional.

3. Todavia, aquilo que mais duradoura e profundamente marcou o movimento académico coimbrão ao longo dos últimos 150 anos, e o destaque do seu lugar no contexto de desenvolvimento da comunidade nacional, foi, como terceira e última das tendências atrás enunciadas, o seu envolvimento em iniciativas dotadas de uma elevada responsabilidade política, visando intervir muito activamente nas transformações operadas na sociedade portuguesa e, por vezes, na definição do próprio regime. Mais intensa e perturbante, é também esta vertente aquela que tem sido abordada de forma mais superficial, sendo, por este motivo, mais facilmente apagada da memória residente das ulteriores gerações de estudantes.

$\mathrm{Na}$ Primavera de 1828, alguns dos lentes que iam a Lisboa, por deputação das autoridades universitárias, beijar a mão a D. Miguel, monarca absoluto, foram agredidos e assassinados na aldeia de Sangardão, perto de Condeixa-a-Nova, por um grupo de estudantes liberais mais exaltados. Esta acção marcou a sangue o início de uma intervenção estudantil nas grandes questões da ordem política, confirmada pouco tempo depois pela intervenção dos batalhões académicos em diversos conflitos, especialmente durante os tempos difíceis da Guerra Civil (1832-34) e da Patuleia (1846-47). Nesse tempo 
conturbado, tornou-se mesmo corrente a prática da passagem administrativa dos alunos matriculados, esvaziando a cidade dos seus estudantes e concedendo-lhes, sem contratempos processuais, a oportunidade para se dedicarem a salvar a pátria. Terá sido, porém, a já recordada Sociedade do Raio, a assumir claramente a intervenção estudantil enquanto espaço-tempo de preparação dos estudantes para uma intervenção que deveria ser perspectivada, como a própria proclamava, para "fora daqui" (Manifesto apud Nóvoa, 1991: 277). Por isso a realidade do país, no seu conjunto, esteve tão presente nas razões que determinaram esta acção académica, projectando-a para além dos limites do meio universitário e da cidade, mobilizando um conjunto de referências internacionais no plano das ideias, e definindo como objectivo essencial, na palavra dos seus próprios agentes, "livrar um século novo do fantasma doutro século morto e enterrado" (Ibidem: 282).

O alargamento do grau de politização do movimento associativo e estudantil coimbrão e o seu empenho em iniciativas apontadas contra o regime, verificaram-se, entretanto, na fase posterior ao 28 de Maio e à implantação da Ditadura Militar. Nessa altura, dentro de uma área social já adaptada à intervenção pública que tinha sido estimulada pelo ambiente cívico vivido durante a I República, foi no sentido de assegurar a sua defesa que foram lançadas diversas acções estudantis. Derrotada por um regime que entrava então nos anos da estabilização política e da afirmação junto de largos sectores da população que se seguiram imediatamente à proclamação do Estado Novo, este tipo de intervenção quase desaparecerá de seguida, durante o período que se prolongou até ao fim da Segunda Guerra Mundial e à integração de amplos sectores estudantis nos actos de uma oposição que, após a vitória militar dos aliados, por instantes acreditara encontrar-se próxima do poder. A eleição de uma direcção associativa chefiada por Francisco Salgado Zenha, em assembleia-geral de estudantes que teve lugar em 1944, foi um sinal desse tempo fugaz: os dez anos seguintes corresponderão, de facto, a uma altura na qual o associativismo estudantil se manteve em posição defensiva. Tal aconteceu no interior de um ambiente cultural definido, muito particularmente no caso de Coimbra - na sua condição de centro de reduzidas dimensões, fortemente marcado pela actuação de índole conservadora dos círculos próximos do salazarismo, pelo provincianismo do meio e pela origem rural da larga maioria dos seus corpos - por intermédio de um nítido deslocamento em relação às práticas sociais e às iniciativas culturais que vinham já sendo detectadas junto dos ambientes urbanos alargados, mais complexos e abertos a uma razoável influência cosmopolita, junto dos quais as outras grandes academias nacionais se vinham definindo. 
Apenas no decorrer dos anos 60 esta situação será verdadeiramente alterada. Este período é aqui tomado como na sua longa duração e máxima amplitude geográfica, abrangendo sensivelmente duas décadas, cujo início remonta sensivelmente à segunda metade da década de 1950, com a rápida emergência de uma subcultura juvenil autónoma e a afirmação de renovados movimentos de emancipação social e nacional, e encerrando com o final dramático da experiência democrática chilena e o termo do processo revolucionário português, provavelmente os derradeiros momentos de tensão "sessentista" entre revolta e utopia (Jameson, 1984). Durante essa época, aquilo que outrora fora concebido como zona de consenso - ou seja, o universo de um saber que conseguia atravessar as gerações, diferentes segmentos sociais e o próprio sistema educativo - vinha aí sendo transformado em campo de batalha, ao mesmo tempo que a cultura passava "de parte da solução a parte do problema" (Eagleton, 2003: 57). Isto significa que a afirmação de uma nova cultura-mundo, de dimensão planetária, se fez então em pleno combate contra as matrizes dominantes da modernidade, funcionando ao mesmo tempo enquanto base energética e campo de influência de toda a corrente contestatária. Será, porém, no contexto das alterações operadas dentro de um universo juvenil em fase de expansão que se tornará possível detectar a origem de boa parte das grandes transformações que ocorreram na época, bem como do ponto de não retorno que, em particular no que respeita à afirmação de uma atitude recorrente de protesto anti-disciplinar (Stephens, 1998), elas puderam configurar.

Um número importante de jovens, particularmente aqueles que povoavam os espaços urbanos e universitários, questionavam agora a sua transformação - até essa altura tomada como um dado adquirido, mesmo entre a generalidade dos sectores de oposição - em meros porta-vozes dos impulsos políticos e das expectativas culturais das suas elites de origem. Assumiam-se como sujeitos sociais que questionavam e contestavam o seu modo de inserção na sociedade, constituindo a sua própria condição juvenil o objecto de interesse em redor do qual foram capazes de construir a sua área de intervenção política. Não era apenas nova a existência de jovens associados às formas de crítica, contestação e rebeldia, com as quais confrontavam as autoridades, mas era igualmente novidade que, a um ritmo cada vez mais veloz, eles se mostrassem em condições de apresentarem alternativas, ou fossem capazes de empreender uma acção distinta da dos mais velhos, e por vezes se lhes opusessem. Afirmava-se, enquanto facto totalmente incontornável, a sua própria visibilidade social.

Esse lugar distinto emergia também como território de resistência, dentro do qual se desenvolvia uma existência específica, social e culturalmente 
desenraizada, capaz de afirmar um "viver entre parêntesis" (Pietrocolla, 1996), idealmente percorrido numa dimensão transnacional, que conferia aos meios juvenis, e nesta fase particularmente aos universitários, uma autonomia - longe da família, distante do trabalho - que suscitava, ao mesmo tempo, o distanciamento e mesmo a recusa em relação às condicionantes do meio envolvente.

No espaço tradicionalmente ensimesmado da antiga cidade universitária, produziram-se assim, nesta fase de intensa mudança geracional, modalidades de uma subcultura de elevado potencial subversivo, as quais, crescendo no mesmo ambiente físico, se foram gradualmente alargando e separando dos localismos e das formas de exaltação do nacional que resistiam a essa lenta mas poderosa invasão. Pode dizer-se que foi nesse contexto que a academia de Coimbra viveu, em plenos anos 60, uma das mais notáveis transformações da sua história. Já não o núcleo restrito e incontornável, quase exclusivamente masculino, ocupado com a produção de um sector indispensável das elites, já não o fiel instrumento de reprodução de uma concepção do país e do mundo que o salazarismo pretendera fixar (Grácio, 1989), mas antes o segmento especialmente dinâmico de um movimento amplamente participado, de uma certa forma inequivocamente internacional (Joussellin, 1969), de resistência aos modelos interpretativos da modernidade autoritariamente impostos e ao papel da universidade como seu caldo de cultura. A intensa politização do meio estudantil coimbrão ocorrida principalmente a partir de 1971, sob a onda de choque do Maio de 68 e a influência de um novo tipo de activismo, apontando já para o aniquilamento do regime, a completa destruição do sistema económico dominante e o fim da guerra colonial, mas contestando também com uma grande radicalidade, tanto ao nível das opções políticas como na área das vivências quotidianas, a "cultura de regime", tem a marca dessa influência.

Enquanto instrumento de resistência, produzia-se uma alternativa à vivência do pequeno mundo, cerrado sobre si próprio, e ao desenvolvimento da Universidade como espaço de alguma forma perverso, ocupado essencialmente - apesar da existência de um número significativo e particularmente honroso de excepções - com o fomento de leituras do mundo que eram cada vez mais radicalmente questionadas. Em alternativa, a cultura juvenil universitária produzia territórios da imaginação que permitiam conceber outras regiões, capazes de funcionarem como paragens de auto-estrada, não-lugares (Augé, 1992) pontuando novos trajectos sem lhes imporem constrangimentos. O mais simples deambular funcionava então como momento libertador da prisão representada por aquele pequeno mundo. Percorrer pontos no mapa, somá-los como elementos de um património individual, 
possibilitou, nestas condições, a produção de uma cartografia do desenraizamento (Bebiano, 2003), que buscava modelos alhures e marcou profundamente os jovens universitários presentes em Coimbra neste período, determinando a sua desafectação em relação ao regime vigente e reduzindo acentuadamente a importância simbólica e vivencial detida pela própria cidade.

No pós-25 de Abril, esta situação ver-se-á alterada de uma forma rápida e profunda, não apenas em consequência da democratização do sistema político, mas, sobretudo, por causa do desenvolvimento de poderosos movimentos sociais, em condições de intervirem na definição dos seus contornos institucionais e programáticos. E devido também à redução do papel destacado da antiga cidade universitária, em grande parte determinada pela marginalização de uma parte significativa das suas elites, directa ou indirectamente comprometidas com o regime derrubado, mas relacionada também com um processo de explosão do ensino superior que já então se podia vislumbrar, embora ainda ninguém se encontrasse em condições de prever as suas avassaladoras consequências.

4. Deste trajecto temporalmente alargado e centrado no caso de Coimbra pode desde já inferir-se uma generalização: grande parte do sucesso das iniciativas estudantis de teor reivindicativo, enquanto fenómeno social de importante significado, dotado de acentuada longevidade, resultou sempre da sua capacidade para ultrapassarem a mera defesa dos interesses próprios e imediatos. Para integrarem movimentos de um carácter mais ambicioso, destinados a intervir em áreas nas quais esses limitados objectivos se transformassem em metas capazes de se reflectirem numa participação cívica de maior alcance. Dentro de uma dimensão planetária, foi nessas ocasiões que se tornou possível instalar as movimentações estudantis num lugar de destaque, fazendo-as alcançar um protagonismo histórico muito considerável, em condições de ultrapassar as fronteiras sociais, ou mesmo as nacionais, dentro das quais haviam permanecido confinadas, e conferindo-lhes ao mesmo tempo um grau de exemplaridade capaz de impulsionar o aparecimento de movimentos de uma natureza social e territorial mais alargada. Nos últimos cinquenta anos, de Berkeley a Tien-An-Men, entre Nanterre e Praga, desde a Cidade do México até Dili ou Seul, tem sido essa iniciativa a pautar, em larga medida, o desenvolvimento político e o empenhamento cívico nas regiões dentro das quais elas tiveram lugar, conferindo à acção estudantil um elevado sentido emulativo e emancipatório, com capacidade para se afirmar na condição de "fenómeno social contínuo e vital, de uma natureza global" (Boren, 2001: 3). 
Por outro lado, apenas conhecendo a sequência interpretativa das suas práticas reivindicativas ou de resistência - isto é, incorporando, na teoria como na acção, a interferência da memória - a maioria dos estudantes se pode encontrar em condições de compreender que as iniciativas nas quais activamente participa, ou com as quais tacitamente convive, representam um meio e não um fim, ao contrário daquilo que acontecia com as iniciativas de feição essencialmente corporativa. Em situação de aceitar que, num mundo dentro do qual nada mais permanece cerrado sobre si, elas representam, ou podem representar, uma etapa para se alcançar algo mais.

Daqui o interesse numa leitura do passado - representado a partir de uma observação de documentos escritos, falados, desenhados, fotografados ou filmados - que se mostre capaz de interpretar áreas do acontecido e de as reintegrar nos processos de compreensão dos actuais fluxos sociais e culturais, em particular daqueles que têm vindo a afirmar-se junto dos meios juvenis universitários. Uma observação ocupada, para o caso de Coimbra, com a especificidade que a sua memória da iniciativa estudantil contém, e com também essa incorporação, constitui um dos vectores essenciais do projecto colectivo de investigação que decorre actualmente no âmbito do CES. ${ }^{1}$

\section{Referências Bibliográficas}

Augé, Marc (1992), Non-Lieux. Introduction à une anthropologie de la Sumodernité. Paris: Seuil.

Augé, Marc (2001), As Formas do Esquecimento. Almada: Íman Edições.

Bebiano, Rui (2003), O Poder da Imaginação. Juventude, Rebeldia e Resistência nos Anos 60. Coimbra: Angelus Novus.

Boren, Mark Edelman (2001), Student Resistance. A History of the Unruly Subject. New York: Routledge.

Bourdieu, Pierre (1984), Homo Academicus. Paris: Minuit.

Cruzeiro, Celso (1989), Coimbra, 1969. A crise académica, o debate das ideias e a prática, ontem e hoje. Porto: Afrontamento.

Eagleton, Terry (2003), A Ideia de Cultura. Lisboa: Temas \& Debates.

Grácio, Rui (1989), "Moral e Política na Academia de Coimbra. Crónica documentada de uma polémica no dealbar dos anos 60", Vértice. II Série, 15, 69-85.

Jameson, Fredric (1984), "Periodizing de 60s", The 60s without Apology. Sohnya Sayres e Anders Stephensom, eds. Minneapolis: University of Minnesota Press. 178-209. Joussellin, Jean (1969), As Revoltas dos Jovens. Lisboa: União Gráfica.

\footnotetext{
${ }^{1}$ Este projecto de investigação intitula-se "Culturas Juvenis e Participação Cívica: diferença, indiferença e novos desafios democráticos”.
} 
Namorado, Rui (1989), "Para uma Universidade Nova - Crónica da Crise de 69 em Coimbra”, Revista Crítica de Ciências Sociais. 27/28, 63-124.

Nóvoa, António (1991), "A Sociedade do Raio na Coimbra académica de 1861-1863", Universidade(s). História, Memória, Perspectivas. Coimbra: Congresso História da Universidade. Vol. 3, 277-320.

Nunes, Adérito Sedas (1968), “A população universitária portuguesa: uma análise preliminar”, Análise Social. 22-23-24 (VI), 295-385.

Pietrocolla, Luci Gati (1996), “Anos 60/70. Do sonho revolucionário ao amargo retorno”, Tempo Social. 8 (2), 119-145.

Stephens. Julie (1998), Anti-Disciplinary Protest. Sixties Radicalism and Postmodernism. Cambridge: Cambridge U. Press.

Valente, Vasco Pulido (2001), Glória. Lisboa: Gótica.

Wieviorka, Michel (1993), "Mémoire, Histoire et Intégration", Mémoire et Intégration. Vv. aa. Paris: Syros. 113-117.

Xavier, Alberto (1962), História da Greve Académica de 1907. Coimbra: Coimbra Editora. 